\title{
CIEN AÑOS DESPUÉS: LOS RASGOS DE MODERNIDAD DE EL SUICIDIO*
}

\section{Javier Callejo}

\begin{abstract}
RESUMEN
El artículo analiza las razones por las que El Suicidio sigue constituyendo un modelo de informe para la investigación social empírica. Para ello, se centra especialmente en la escritura de esta monografía, considerándose que es una escritura que instituye la modernidad en Sociología. Con anterioridad, se ha destacado la naturaleza lingüística del proyecto de Durkheim. Sin embargo, no se han establecido los vínculos entre esta característica del proyecto del autor francés y el conjunto del mismo. Este trabajo ha seguido principalmente las aportaciones de Bruno Latour en el análisis de la modernidad, describiéndola como la institucionalización de la diferencia entre naturaleza y cultura. Para esta labor es fundamental la aportación de dos prácticas: la traducción y la purificación. Tras repasar dos tipos de escrituras sociológicas precedentes, como las de Engels y Le Play, se describe cómo El Suicidio aplica la traducción y la purificación.
\end{abstract}

\section{INTRODUCCIÓN}

Han transcurrido cien años (1897) desde la publicación de El Suicidio, una de las obras clave en la historia de la sociología y una investigación llevada a cabo con la intención de servir de ejemplo del quehacer sociológico (Giddens, 1993: 55). Su título completo es significativo respecto a tal intención modéli-

* Agradezco los comentarios del profesor Ramón Ramos, buena parte de los cuales han sido incorporados al texto. 
ca: Le suicide: étude de sociologie. Ahora bien, esta obra no sólo tiene interés para la historia de la sociología, sino que conserva su fuerza como referencia de sociología empírica, a pesar de las críticas, acumuladas durante un siglo, sobre sus inferencias ${ }^{1} \mathrm{y}$, en general, su contenido. Hay algo en esta investigación, especialmente en la forma de presentarse, que la sigue haciendo atractiva. $E l$ Suicidio tiene algo especial que, como Parsons ${ }^{2}$ se encarga de señalar, pone esta obra en un lugar aparte de la producción sociológica. Desde tal perspectiva, las referencias al contexto histórico, lugar de encuentro de la mayor parte de los estudios sobre la obra, pueden ayudar a explicar la producción del texto; pero no tanto el atractivo que mantiene entre los científicos sociales.

El carácter modélico de El Suicidio sitúa la obra como una de las más relevantes operaciones instituyentes de la sociología. Como operación instituyente, su análisis puede centrarse en el lugar social que reclama, en la práctica "científica» que inaugura o en la escritura que establece, pues combina los tres aspec$\operatorname{tos}^{3}$. Una combinación que instituye la sociología moderna. Aun cuando el presente trabajo se centra en la escritura, no puede perderse de vista su relevancia como reclamación de un lugar social y de aceptación como práctica "científica", pues no cabe entender una escritura de informe moderno sin la asunción de una práctica científica moderna y de los valores de la modernidad en su conjunto. No obstante, se deja a un lado la modernidad de la propia investigación, para acentuar la modernidad del discurso presente en El Suicidio.

Lo que este trabajo intenta mostrar es que buena parte del carácter modélico de esta monografía reposa en su modernidad. Según Kaplov (1974: 10), uniendo ejemplaridad y modernidad, El Suicidio es el prototipo perfecto de informe de investigación social moderna. Manifestación capaz de ser suscrita por buena parte de la comunidad sociológica; pero que permite algún paso más: dada esta idealidad, todo informe de investigación social, tal como ampliamente se entiende, es un ejercicio de modernidad, tanto por el lugar

${ }^{1}$ La principal crítica metodológica a El Suicidio ha consistido en la denominada falacia ecológica: «es el nombre que se da a la falacia de proyectar de arriba hacia abajo, especialmente cuando se hacen inferencias desde unidades geográficas hacia individuos» (Galtung, 1973: 45). Lo contrario de la falacia ecológica es la falacia atomística (Riley, 1963: 706). El primero en señalar el peligro de inferir de la correlación calculada a partir de las propiedades o proposiciones características de grupos a la correlación que se obtendría recurriendo a datos individuales fue Robinson (1950). Para un análisis de la falacia ecológica en El Suicidio, véase Selvin (1958). La falacia ecológica en Durkheim deriva de su propio marco teórico, que parte del carácter general de los hechos sociales, y de la insuficiencia de la generalidad de los fenómenos para convertirlos en tales hechos sociales. Asimetría que inclina a asignar a lo individual las observaciones de lo colectivo, mientras que impide asignar a lo colectivo las propiedades generales de lo individual.

${ }_{2}$ "Hay muy pocas monografías en el campo de la ciencia social donde se combine tan felizmente los aspectos teóricos y empiricos. Porque, sobre la base de lo que parece a primera vista ser un tema empirico muy restringido y especializado, Durkheim consigue llegar a resultados que arrojan una luz sorprendentemente brillante sobre algunos de los problemas más profundos de la teoría sociali (Parsons, 1968: 385).

${ }^{3}$ Idea que Michel de Certeau aplica a la historia: «la operación histórica se refiere a la combinación de un lugar social, de prácticas "cientificas" y de una escritura" (De Certeau, 1975: 64). 
social que propone, como por la práctica científica que refiere, como por su escritura.

La modernidad de El Suicidio se apoya en tres pilares: a) la explícita manifestación de ruptura con lo anteriormente dicho sobre el tema; $b$ ) la utilización de la estadística como «lugar» en el que es posible el vacío y la observación purificada, al igual que los físicos utilizan el laboratorio, lo que lleva a una escritura cuyo referente parece estar en el mismo texto, en forma de cuadros y tablas; c) la reformulación que plantea de la constitución moderna, proponiendo una nueva división entre lo humano y lo no-humano, lo inmanente y lo trascendente. Los dos últimos puntos de modernidad tienen en Latour su principal autoridad. Los tres se encuentran fuertemente vinculados entre sí: la manifestación de ruptura tiene por fuente una recomposición del mundo, y como arma destructiva de las anteriores hipótesis — con las que se rompe- el análisis estadístico; la reformulación de la modernidad tiene como motor la necesidad de acabar con una situación histórica que se prolongaba, y por principal instrumento la capacidad objetivadora del cuadro estadístico. Estos rasgos de modernidad de El Suicidio están inscritos en su escritura y son producto de la misma. Así, El Suicidio es producto de dos trabajos opuestos, siguiendo a Latour: el trabajo de purificación y el trabajo de traducción. Dos trabajos que, en la nueva articulación que establecen entre sí — privilegiado lugar del primero, labor clandestina del segundo- tejen la particular y total modernidad de la obra. Una obra hecha de modernidad.

\section{LOS TRABAJOS DE LA ESCRITURA MODERNA}

Para el más destacado de los biógrafos de Durkheim, Steven Lukes, El Suicidio supone la aplicación del método sociológico, lo cual ya indica un vínculo con la modernidad. Según este mismo autor, El Suicidio es la búsqueda sistemática de la causalidad aplicada a una cuestión (Lukes, 1984: 204). Sistematicidad que es poner orden, asumiendo así la tendencia moderna a la ordenación del desorden percibido. Pero los diferentes vacíos encontrados en algunas de las inferencias que Durkheim lleva a cabo en esta obra quiebran la definición de trabajo sistemático, en mayor medida si el objetivo es servir de modelo. Por otro lado, ha sido reconocido el énfasis en la naturaleza lingüística del proyecto de Durkheim, aunque se deje sólo en el acento en el vocabulario, en el nuevo vocabulario que incorpora (Boudon, 1974: 944; Jones, 1994), más que en su estructura. Sin embargo, hay aspectos de la estructura de la escritura de Durkheim que no han de dejarse a un lado en esa naturaleza lingüística del proyecto del sociólogo francés. Parece legítimo dudar que la gran capacidad de persuasión de la obra de Durkheim (Lukes, 1984: 201) se limite al vocabulario.

${ }^{4}$ Boudon insiste en que El Suicidio supone un cambio de lenguaje en la sociología, pues rompe con el lenguaje de Stuart Mill, algo que no llega a conseguir Tarde, ni el propio Durkheim en el resto de su obra. 
¿Qué es lo que hace moderno a El Suicidio? ¿En qué se diferencia este informe de los que podrían considerarse como no modernos o premodernos? Al menos, ¿en qué se diferencia de las escrituras de la investigación social que le preceden? El propio Kaplov apenas ofrece explicaciones que fundamenten su afirmación de modernidad de El Suicidio. A la misma, le sigue una serie de descripciones que pueden tomarse como los rasgos de modernidad en el informe según este autor:

- El tema es un problema social interesante.

- Datos obtenidos de archivos y encuestas anteriores.

- Análisis original de los datos.

- Desarrollo de la parte teórica.

- Definición del marco de la investigación.

- Examen de las teorías anteriores.

- Producción del significado de las estadísticas.

- La reformulación de las hipótesis a partir de la confrontación de los datos.

No todos estos rasgos pueden considerarse como modernos y, sobre todo, algunos de ellos apenas diferencian El Suicidio de los estudios sociográficos desarrollados durante el siglo XIX, como ocurre, por ejemplo, con el referido «interés social del tema». Al problema de la escasa definición de Kaplov se une la dificultad de dar significado a un calificativo como el de "moderno». Un término que hay que reconocer sumamente ambiguo ${ }^{6}$, a pesar de que "a las puertas ya del siglo XXI, la cuestión de la modernidad, su desarrollo en el tiempo $y$ sus actuales formas institucionales se ha vuelto a plantear como un problema sociológico fundamental» (Giddens, 1995: 9). Es más, cabe afirmar que en la medida que se ha erigido en un problema sociológico fundamental ha incrementado el grado de su ambigüedad. Una importancia que aumenta a partir de las voces que, como la de postmodernidad ${ }^{7}$, parecen dar fin al dominio de lo moderno,

5 Sobre el interés de Durkheim por el suicidio, Lukes (1984) aporta una explicación personal-biográfica y cinco de carácter colectivo o no personal, lo que hace pensar que el tema tenía un especial interés en la sociedad de Durkheim.

${ }^{6}$ Zygmunt Bauman (1990) es el autor que más hincapié ha hecho en la ambivalencia de la modernidad, arrastrando a otros autores a proyectarlo en la postmodernidad (Elliot, 1996). Una ambivalencia que, como subraya en su última obra (Bauman, 1992), tiene por origen la asunción por parte de la modernidad de la tarea de fundar un orden, tras el reconocimiento de la vulnerabilidad y contingencia del orden humano. Ambivalencia que está presente en la propia obra de Durkheim. En cualquier caso, parece que entre lo que se atribuye como directamente propio y esencial de la modernidad, como resultado del proceso de modernización, sobre el que existe mayor acuerdo, y lo que continuamente se le añade como propio de la misma, ya sea incluyendo lo escondido (Toulmin, 1990) o las manifestaciones que proponen darle fin (Calinescu, 1987), el término moderno agranda sus referencias y pierde precisión.

${ }^{7}$ Hecho que lleva a que la conceptualización de la modernidad sea abordada principalmente por la mayor parte de las obras sociológicas que se enfrentan a la descripción de la postmodernidad. Así, en textos más generales, puede comprobarse cómo la voz modernidad sólo aparece cuan- 
planteándose como uno de los principales debates si la centralidad de la crisis es elemento de la modernidad o es un síntoma de su final. No se entrará aquí en tal debate, a pesar de que indirectamente ocupe un lugar importante en la obra de Durkheim, entendida como respuesta moderna a los problemas de la modernización ${ }^{8}$. Para los propósitos de este artículo, centrado en la modelación de una forma de escribir la investigación social, es de gran utilidad la caracterización que hace el sociólogo de la ciencia Bruno Latour de la modernidad.

En Nunca hemos sido modernos, Latour redefine la modernidad bajo la sombra de la crisis del medio ambiente y el fracaso del socialismo. Una modernidad que pone a un lado la naturaleza y al otro, sin posibilidad de contacto, la actuación de los humanos. Concepción de la modernidad que sigue la obra de Shapin y Schafer (1985) sobre cómo Boyle y Hobbes crean el contenido y el contexto de lo que es ciencia y lo que es política, respectivamente. A Boyle y Hobbes les unían muchas cosas y les separaban pocas; pero la modernidad acentuó la separación de tal manera que terminó ocultando las amplias áreas de contacto. A partir de esta iluminación, Latour basa la modernidad en cuatro puntos:

- Significado 1: Una aceleración del tiempo.

- Significado 2: Un comportamiento de conflicto y discusión, donde constantemente salen vencedores y vencidos.

- Trabajo 1: Prácticas de creación de nuevos híbridos entre la naturaleza y la cultura (trabajo de traducción) ${ }^{9}$. Prácticas que unen mundos previamente separados en las prácticas y las representaciones ${ }^{10}$.

do se enfocan las posibilidades de una sociología postmoderna; véase, por ejemplo, el manual de Ritzer (1993). Cabe subrayar cómo los autores autodefinidos como modernos y más críticos con las características de la postmodernidad hacen hincapié en lo difuminado de éstas — «una estructura de sentimiento", siguiendo a Raymond Williams - en cuanto estrategia ideológica destinada a acabar con los valores de la modernidad en el capitalismo tardío (Jameson, 1991).

${ }^{8}$ Parece operativa la separación, tal como realiza Lyon (1996) entre modernización — procesos económicos, institucionales, etc.- y modernidad, elementos culturales, que pueden entenderse como consecuencia de la modernización. Separación que, por ejemplo, no está clara en el análisis que hace Giddens de las instituciones «de la modernidad» en su obra Consecuencias de la modernidad (Giddens, 1990).

${ }^{9}$ El concepto de traducción es ampliamente utilizado por los sociólogos de la ciencia de la corriente del actor-red. No siempre con el mismo significado. En otro texto distinto a Nunca hemos sido modernos, Latour define por traducción «a la interpretación que los constructores de hechos hacen de sus intereses y de los intereses de la gente que reclutan" (Latour, 1992: 106). Para Callon, se trata de un proceso general «durante el cual se negocia la identidad de los actores, sus posibilidades de interacción y sus márgenes de maniobra» (Callon, 1995: 263). Ambos significados del concepto son matizadamente distintos al utilizado aquí. Para una panorámica de la corriente actor-red, véase Callon (1989).

${ }^{10}$ Aun cuando Latour sitúa explícitamente como modernos los dos trabajos - traducción y purificación-, la lectura del texto hace pensar en períodos previos a la modernidad donde sólo cabe el dominio de la traducción, donde todo está relacionado con todo. 
- Trabajo 2: Prácticas de creación de dos zonas ontológicas claramente diferenciadas, la de los seres humanos, por un lado, y la de los no humanos, por otro (trabajo de purificación).

Si los dos primeros puntos (significados) pueden considerarse un lugar común en las descripciones de la modernidad ${ }^{11}$, la originalidad reside en el análisis de la modernidad a partir de los dos últimos (trabajos). Es más, el trabajo de purificación es la clave de lo que Latour denomina Constitución Moderna. Una Constitución cuyas garantías nunca se han cumplido realmente. Garantías que aseguran: a) la dimensión trascendente de la naturaleza (su objetividad) o la no humanidad de la naturaleza; b) la dimensión inmanente de la sociedad (su subjetividad) o la humanidad de lo social; c) separación de poderes, manteniendo las dos ramas de gobierno en compartimentos separados e impermeables (cuestión que hace que el trabajo de traducción-mediación pase a la clandestinidad); d) función de arbitraje por parte de un Dios suprimido.

Desde esta obra de Latour, la modernidad es la institucionalización de la diferencia entre naturaleza y cultura ${ }^{12}$. Un ejercicio que, a la vez, crea la noción de naturaleza, poniendo entre paréntesis la de cultura, y crea la noción de cultura, poniendo entre paréntesis la noción de naturaleza. Respectivas creaciones de naturaleza y cultura se establecen sobre el trabajo de purificación-diferenciación, siendo éste en el que más hincapié hace la Constitución "oficial», como la llama Latour. Pero bajo esta Constitución, tras el trabajo de purificación, surge el trabajo extraoficial de traducción y mediación (Latour, 1993: 186). Concepción que lleva a que no se cumpla realmente el proyecto moderno y al incumplimiento de su Constitución «oficial»"

La configuración de la modernidad por parte de Latour no es siempre transparente, sufriendo las opacas tendencias de la escritura postmoderna (Gellner, 1994: 37). Además, aparece demasiado uniforme para enfrentarse a los complejos procesos contenidos en la categoría de modernidad. Se presenta la modernidad como un bloque sin presencia de etapas, crisis o quiebras, cuando experimenta distintas concreciones a lo largo de su historia, siendo aquí donde entra el contexto específico en el que se desarrolla la obra de Durkheim. Un contexto histórico dominado por la sensación de crisis de la propia moder-

${ }^{11}$ A estos dos elementos comunes en las caracterizaciones de la modernidad, cabría añadir el del objetivo de la "realización progresiva de la emancipación social e individual en la escala de la humanidad» (Lyotard, 1990: 89), que parcialmente puede entenderse incluida en la última parte de El Suicidio, cuando la obra se introduce en las consecuencias pragmáticas de los resultados.

${ }_{12}$ La Constitución Moderna que garantiza una división de poderes: «a la ciencia pertenece la representación de lo no humano, pero tiene prohibida toda posibilidad de apelación a la política» (Latour, 1993: 49).

${ }^{13}$ Según Latour, el mundo moderno ha aireado más el trabajo de purificación que el de mediación-traducción. De hecho, Latour, como la mayor parte de los buscadores de redes que componen los Science Studies, fundamenta su originalidad en la revelación de mediaciones entre la ciencia, lo social y la política. 
nidad. De hecho, cabe entender la obra del autor francés con el objetivo de reformar y reforzar la modernidad, de pasar de una primera modernidad en crisis a una segunda modernidad renovada. Una segunda modernidad que, dentro del marco propuesto por Latour, conlleva una reformulación de la separación entre lo humano y lo no humano, entre lo trascendente y lo inmanente. La apuesta de Durkheim es: tratemos lo humano como si fuera no humano. Si la observación del mundo de lo no humano (física, medicina) ha logrado importantes éxitos permitiendo defenderse de parte de las consecuencias de sus leyes, ¿por qué no intentar abordar la crisis social con idéntica lógica? La respuesta es: manténgase la frontera; pero pásese la sociedad al mundo de la naturaleza, de lo no humano: tratemos lo humano como si fuera no humano, lo inmanente como si fuera trascendente. Seamos más modernos, es la consigna de Durkheim desde los parámetros de Latour.

Traducción y purificación no son sólo prácticas que fundamentan la modernidad por su aplicación a las relaciones entre naturaleza y cultura. Definen a ésta en cuanto constante ejercicio de renovación, que exige separar y separarse, purificar — seres humanos de no humanos, tradición de no tradición, cada disciplina concreta de otras disciplinas, cada ejercicio de los ejercicios anteriores, etc. - y, así, purificarse. La modernidad, como extensión de la práctica de purificación, explica, entre otras cosas, la angustia innovadora presente en la misma, que hace de la creación su bandera ${ }^{14}$, y del método, tan presente en Durkheim, su instrumento purificador por antonomasia. En esta renovación constante, se purifica en cada disciplina con la indicación de lo que ya no sirve, donde el método lleva a cabo la tarea de combustión, para dejar el campo abierto a la creación. Si la escritura moderna se presenta como ejercicio de purificación, la traducción surge tras la purificación y se revela como acto de imposibilidad de la propuesta moderna: no se puede dejar el mundo en lo trascendente - como naturaleza siguiendo sus propias leyes, como fría descripción de objetos en la escritura- desde un proyecto intrínsecamente inmanente, generado para actuar sobre el mundo, para que lo humano se imponga a lo no humano (objetual o divino). Ello no es obstáculo para que el trabajo de purificación siga siendo la apuesta moderna.

La traducción adquiere valor a partir del trabajo previo de purificación y, a su vez, éste, si no quiere verse condenado a un trabajo analítico infinito, encuentra su sentido en los horizontes de traducción. Prácticas fundamentales de la modernidad, traducción y purificación se proyectan en la escritura de las más diversas maneras, aun cuando aparecen como dominantes dos estrategias: la definición en la purificación y la estrategia trópica en la traducción. Teniendo en cuenta que es tan retórico utilizar como no utilizar los más floridos tropos de la retórica, la purificación, heroicamente (Gross, 1990: 17), hace desaparecer los tropos de la escritura; mientras que la traducción usa los posibles

${ }_{14}$ En este aspecto, la postmodernidad se presenta como ejercicio de bricolage de lo ya creado, de la lógica de las mezclas, renunciando a la creatividad original. 
tropos, especialmente la analogía y el desplazamiento ${ }^{15}$. La definición como labor clave en la separación entre lo que es y lo que no es. La analogía, al igual que otros juegos trópicos de la escritura, es clave para relacionar campos que el hábito no pone en contacto, extendiendo lo hasta ahora poco conocido o desconocido, a partir de lo conocido (Perelman y Olbrechts-Tyteca, 1989). A partir de estos juegos retóricos, se unen lo que es y lo que no es, creando el marco para la generación de híbridos entre la naturaleza y la cultura.

Con la proyección de purificación y traducción en la escritura de la investigación social, se entra en la sociología como texto. En su propuesta de herramientas para el análisis de la sociología como texto, Ramón Ramos ${ }^{16}$ distingue entre arquitectura, poética y retórica del texto. A través del análisis de la arquitectura del conjunto del texto, cabe observar en qué partes del mismo domina la purificación o la traducción; el análisis de la poética, el dominio de cada uno de los trabajos en la escritura; mientras que la retórica, entendida como pragmática del texto (lo que quiere hacer el texto) en el contexto, se ofrece como guía para el análisis de la relación con la modernidad. Propuesta analítica que conducirá la mayor parte del resto del trabajo.

\section{INFORMES ANTERIORES}

Si El Suicidio es prototipo de informe moderno, las anteriores escrituras sobre investigaciones sociales toman la categoría de informes no modernos o, al menos, con carencias para ser modernos. Con el objeto de comprobar la carencia de modernidad, a partir de los criterios establecidos en el apartado anterior —en especial el dominio del trabajo de purificación — se abordan dos trabajos: La situación de la clase obrera en Inglaterra, de Engels; la monografía sobre una familia de Cantabria, de Le Play. Al realizar un mero resumen de estas obras y con objeto de no tener que retomar lo dicho con posterioridad, ha sido necesario recurrir a El Suicidio en algunas ocasiones para facilitar la comparación inmediata.

El informe de Engels La situación de la clase obrera en Inglaterra fue escrito en 1844 y publicado por primera vez en Alemania en marzo de 1845, cuando su autor tenía veinticuatro años (Engels, 1981). El objetivo de la investigación es tan general como difuso: describir la realidad de la clase obrera de la primera nación industrial. Como ocurre con la mayor parte de la investigación sociográfica de la época, el informe se convierte en una especie de inventario. El propio Engels reconoció este aspecto a Marx ${ }^{17}$, aun cuando dejó a un lado que

15 En otro lado, el mismo Latour une traducción y ciertas figuras retóricas: "He usado en varias ocasiones las palabras "traducción", "transferencia", "desplazamiento" y "metáfora", que quieren decir lo mismo en latín, griego y español” (Latour, 1995: 246).

${ }^{16}$ Comunicación personal.

17 Carta de 1844 a Marx, reproducida en el apéndice de las obras completas (Engels, 1981). 
se trataba más de un inventario de impresiones ${ }^{18}$ que de datos. ¿Qué hace de esta obra un informe, una escritura de investigación social? El estar, como reclama el subtítulo de la misma, basada en la experiencia directa y en fuentes auténticas. Se presenta como producto de un trabajo de investigación, aun cuando las denominadas fuentes auténticas sean reproducciones extensas de los periódicos locales y una acumulación de los diferentes informes fabriles y médicos.

En cuanto a su arquitectura, La situación de la clase... es la exposición de los procesos sociales generales (renovación técnica en la siderurgia, la agricultura, la industria textil y las comunicaciones, la urbanización, etc.) que condicionan la situación de la clase obrera. Su lugar social no reside en el ámbito de las disciplinas, sino en el de la política. Tampoco se reclama una práctica científica. Mucho menos se plantea una nueva división entre el mundo humano (inmanente) y el mundo de los objetos, no-humanos (trascendentes): si se reclama una acción política inmediata es porque el mundo enfocado aparece como inmanente, como acción de sujetos, identificados en la burguesía. De aquí que el trabajo de purificación apenas tenga lugar.

En cuanto a su poética, el dominante trabajo de traducción se refleja en la abundancia de tropos: "los trabajadores vegetaban", "sorda cólera», "apéndice del capital», "fue necesario que permanecieran ahogadas e inertes cientos de fuerzas", "guerra social», "desintegración de la humanidad en mónadas», "asesinato social», etc. Incluso en las definiciones se apoya en metáforas: "La competencia es la expresión más acabada de la guerra de todos contra todos reinante en la moderna sociedad burguesa» (Engels, 1981: 345). El afán por traducir la realidad, sin un trabajo purificador previo, le lleva a la descripción del detalle: "en tiempo seco, esta orilla queda cubierta por una larga sucesión de repugnantes charcos de color verdinegro, del fondo de los cuales brotan constantemente burbujas..." (Engels, 1981: 323); "alli se pasan las largas horas, encorvados sobre la labor, trabajando desde las cuatro o cinco de la mañana hasta media noche» (Engels, 1981: 457). La descripción roza, a los ojos del científico social de hoy (postdurkheimiano), la sensación morbosa de lo sobrante: "La mujer yacía muerta junto a su hijo sobre un montón de plumas extendidas sobre el cuerpo casi desnudo, pues por ningún lado aparecian ni colcha ni sábanas» (Engels, 1981: 307). Se unen la retórica populista (sensacionalismo, podría llamarse hoy) con la retórica del "autor estuvo ahí», una retórica de amplio dominio entre la etnografía (Geertz, 1989), la historia ${ }^{19}$ y

${ }_{18} \mathrm{Al}$ contrario que Engels, Durkheim rechaza las primeras impresiones, la percepción no sistemática.

19 En griego, historia y cierta idea de testificar («hasta donde puede ver») son sinónimos (Lampe, 1987). En esta línea, Lledó sitúa el origen de la palabra historia en conexión con "testigo de vista", como: "El saber que brota de un testimonio semejante tiene como fundamento la experiencia» (Lledó, 1978: 94), donde la autoridad reside en ser testigo presencial. Lozano, apoyándose en Lledó y en discusión con Benveniste, une historia y testigo: "podemos proponer la investigación histórica como una observación en la que el investigador es testigo, puede dar cuenta de lo que ha visto, es decir, sabe porque ha visto" (Lozano, 1987: 18). Mientras Engels y Le Play utilizan esta 
la sociografía ${ }^{20}$, donde lo existencial, la propia experiencia, se convierte en único elemento de validación ${ }^{21}$. Como mediador de la realidad, el autor no puede desaparecer en favor del método, que, entre otras funciones, purifica la presencia del propio autor. Un autor que se reconoce al lector como relator subjetivo $^{22}$ : "releyendo ahora lo que he escrito, debo reconocer que mi relato, lejos de exagerar la repugnante realidad, más bien se queda corto" (Engels, 1981: 326).

La falta de modernidad en la escritura, a pesar de las referencias empíricas subrayadas, se liga a cierto rechazo de la modernidad en su conjunto, lo que provoca algunos comentarios críticos e irónicos sobre algunos de sus defensores: "iSe han preocupado acaso de sacar de sus modernos Libros Azules una sola obra legible que permita a cualquier lector enterarse sin esfuerzo de cuál es la verdadera situación de la gran mayoría de los ingleses "nacidos libres"?" (Engels, 1989: 282). Para Engels, la modernidad es la burguesía y el reciente desarrollo técnico, es decir, aquello contra lo que se enfrenta. La práctica inexistencia de partes de su arquitectura dominadas por el trabajo de purificación, una poética regida por tropos y la sospecha de la modernidad como situación histórica, hacen que este informe sea poco moderno.

Les ouvriers des deux mondes, de Le Play, es una colección-mosaico de monografías que toma el aspecto de un gran inventario, con su valor a un lado (en francos), en el apartado referido a los medios de vida de cada una de ellas. Aquí se toma como referencia una de las monografías, la realizada sobre una familia campesina cántabra ${ }^{23}$. Obra caracterizada por el papel preponderante de la descripción. Una descripción que es como una especie de microenciclopedia de los hábitos y costumbres de la familia observada ${ }^{24}$, apoyándose en la

vía de autoridad — saber a través de la experiencia propia—, Durkheim, sobre todo a partir de la presentación de cuadros estadísticos, invita al lector a hacerse testigo. Durkheim hace uso de la misma estrategia que Boyle en su laboratorio (Latour, 1993): convierte en testigos a los presentes en el mismo durante el experimento. En El Suicidio, el laboratorio es el cuadro estadístico, y el experimento, las relaciones entre los hechos sociales.

${ }^{20}$ El haber estado ahí es lo que justifica el hecho de haber elegido Manchester como ciudad industrial de referencia: "porque yo la conozco como si fuera mi propia ciudad natal" (Engels, 1981: 317). El "estuvo ahí» domina sobre la articulación con la teoría: "He enumerado los diferentes barrios de Manchester, tal como he tenido ocasión de observarlos por espacio de veinte meses» (Engels, 1981: 335).

${ }^{21} \mathrm{La}$ ausencia de un orden justificado por un trabajo de purificación previo lleva a que esta investigación asuma como único orden el de «la propia realidad», tal como puede entenderse el orden cronológico: "El orden en que habremos de estudiar los distintos sectores del proletariado se desprende por si mismo de la historia de su nacimiento, expuesto en páginas anteriores» (Engels, 1981: 299).

22 Desde este aspecto, Durkheim sólo toma la palabra, se asume como sujeto en la escritura, tras la presentación de los hechos.

23 "Familia campesina de Revilla de Camargo (Santander), 1840-1847», de Le Play (1990), aparece en la primera edición de Les ouvriers européens (pp. 176-181 de la primera edición), en el capítulo V (pp. 247-290) del tomo IV de la segunda edición (Tours, Alfred Mane et Fils, 1877).

${ }^{24}$ Descripciones como: «Las jarrepas son una papilla espesa de leche que normalmente se toma metiendo la cuchara alternativamente en el recipiente en el que se han preparado y en otro lleno de leche fría» (Le Play, 1990: 83). 
comparación de lo visto en un lugar a lo visto en otros lugares ${ }^{25}$. De arquitectura inventarial, su poética está dominada por el trabajo de traducción, proponiendo híbridos entre la naturaleza y las poblaciones respectivas, entre cántabros, bretones y rusos, entre genes y culturas. Todo aparece relacionado con todo a partir de la afirmación de oportunas comunidades de rasgos. Sin trabajo de purificación, todo aparece como impregnado de lo mismo ${ }^{26}$.

La racionalización ingeniera, que se encuentra tras la convocatoria de esta recolección de monografías descriptivas para la reforma social, puede considerarse moderna. Pragmáticamente puede considerarse una obra moderna; pero su expresión escrita aún no lo es del todo. Se parte de una posición modernaracionalizadora como criterio de evaluación de lo visto, realizado casi siempre en clave crítica: "La mayor parte de los aparceros de la región, desprovistos de todo sentido del orden y de la previsión" (Le Play, 1990: 111); pero sólo queda como una capa ideológica, como una perspectiva, que no se proyecta en el desarrollo del escrito, hasta el punto de que las conclusiones (capítulo 18) no están relacionadas con lo anteriormente expuesto.

En el propio Durkheim hay monografías previas a El Suicidio. Incluso puede afirmarse que, en muchos aspectos, El Suicidio tiene su germen en La división del trabajo social (1982a), publicado cuatro años antes (Miley y Micklin, 1972), o en el artículo "Suicidio y natalidad» (1975). Sin embargo, entre estas obras hay diferencias lo suficientemente importantes como para afirmar la modernidad de la publicada en segundo lugar y mantener entre parénteses la de las primeras. Las difusas referencias empíricas de La división impiden la génesis de un ámbito trascendente, no humano, que separar del mundo humano e inmanente. Por lo tanto, no hay materia para el trabajo de purificación. No hay, utilizando términos del propio Durkheim, una «materia prima» que haga del "estado moral» un conjunto de hechos en los que "descubrir en ellos algún elemento objetivo que suponga una determinación exacta, $y$, si ello es posible, la medida» (Durkheim, 1982a: 45).

En «Suicide et natalité, étude de statistique morale» (Durkheim, 1975), antecendente inmediato de El Suicidio, que contiene un importante despliegue de tablas estadísticas, carece de la manifiesta concepción del mundo presente

25 Comparaciones que llevan a afirmaciones como: «España se parece, desde este punto de vista, a Rusia» (Le Play, 1990: 76). Comparaciones entre un lugar y otro como, ya sea realizando equivalencias particulares: "por una particularidad semejante a la que se produce en otras zonas montañosas de Europa -y especialmente en los Alpes montañeses—" (Le Play, 1990: 75), "de ahi las importantes analogías existentes entre las costumbres de estas poblaciones» (Le Play, 1990: 111), "el arriero, equivalente exacto del izvostchik ruso» (Le Play, 1990: 112), "Esta costumbre es idéntica a la que aparece entre los bachkirs, los rusos, los bearneses y los bretones» (Le Play, 1990: 86), o equivalencias generales: "Estos territorios presentan aqui las mismas ventajas y los mismos inconvenientes que en todas partes se derivan de los bienes comunales» (Le Play, 1990: 76).

${ }^{26}$ Le Play compara sin purificación previa. De hecho, los cuadros utilizados por este autor no son proyectados hacia la comparación, siendo ésta una de las principales críticas que recibirá de los discípulos de Durkheim, como Halbwachs (Desrosières, 1993: 264). Por el contrario, Durkheim compara desde la purificación previa en el cuadro estadístico. 
en Las reglas del método sociológico. Si en La división del trabajo social Durkheim no utiliza la estadística, en «Suicide et natalité» utiliza el análisis estadístico como sus predecesores, como un instrumento, y no como un espacio en el que dirimir una concepción del mundo ${ }^{27}$, razón por la cual el artículo precedente se mantiene dentro de la "estadística moral» y no dentro de la sociología, como se reconoce en su título.

«Suicide et natalité» es un texto en el que el trabajo de traducción, especialmente destinado a asimilar el estado de la sociedad con los estados de salud o enfermedad ${ }^{28}$, apenas deja lugar para trabajo de purificación, que hubiera debido ser previo. Sobre todo el texto planea el híbrido cuerpo-sociedad. Así, el suicidio no es un hecho - algo no humano (individual), como subrayará en El Suicidio_-, sino sólo un síntoma de malestar social. Los cuadros estadísticos presentes en el artículo aparecen destinados más a mostrar la gravedad del síntoma que a enfocar sus causas, dejándolas en una vaga referencia a la profundidad: "causas morales más profundas» (Durkheim, 1975: 230). Pero, sobre todo, el trabajo de purificación apenas aparece porque los hechos sociales siguen estando del lado humano en este artículo. No son como cosas, concepción que seguramente hubiera evitado el situar como una de las posibles causas indirectas del aumento de suicidios y el descenso de la natalidad algo que hubiera exigido una mayor cosificación, como es el «espíritu doméstico».

\section{LA RUPTURA}

Obra amplia y profundamente conocida por la comunidad sociológica, El Suicidio apenas necesita presentaciones. Sin embargo, conviene recordar su arquitectura, en cuanto orden más superficial del discurso, y el dominio en cada una de sus partes de los trabajos de purificación o traducción.

La primera parte del trabajo es una práctica de purificación continua ${ }^{29}$.

${ }^{27}$ En «Suicide et natalité», se limita a establecer comparaciones de cifras de suicidios y de natalidad en la tabla estadística, apuntando a un algo común que explica esa relación entre ambas, por lo que una natalidad extrema conduce al aumento de suicidios; pero no llega a designar tal "algo», lo que obliga a aceptar la natalidad en el doble papel de causa y efecto de ese «algo».

${ }^{28}$ Dentro de la poética, el conjunto de la obra de Durkheim es el paso de una metafórica bio-organísmica a otra de orden físico. "Suicide et natalité» es bio-organísmico y El Suicidio una obra de paso en el marco de esa poética. Precisamente por la centralidad bio-organísmica de la primera no consigue pasar la frontera hacia el separado mundo de las cosas, de los objetos naturales con sus propias leyes, pues todavía queda un residuo de acción humana. En la primera parte de El Suicidio, donde con más ahínco se desarrolla el trabajo de purificación, tal metafórica está ausente. No obstante, reaparece al final, cuando la modernidad (separación entre lo cultural y lo natural) se traiciona nuevamente a sí misma, creando nuevos híbridos.

${ }_{29} \mathrm{Al}$ principio, hay que prescindir de la traducción: «conviene prescindir de estas traducciones, para atender mejor al texto original de donde procede todo su sentido, y al que a veces desnaturaliza» (Durkheim, 1982b: XXIX), refiriéndose a la realidad como texto original. En las primeras páginas, Durkheim purifica para construir una sociología pura (Durkheim, 1982b: XXVI). La conciencia del extenso trabajo de purificación, de desecho de lo que no vale, desarrollado en el 
Puede decirse que la fuerza de la monografía se encuentra en el intenso trabajo de purificación llevado a cabo por Durkheim. Un trabajo de purificación que se proyecta en:

a) Separarse de lo que se ha hecho hasta el momento, como la ubicación de los hechos sociales en el lado de lo humano: "(la sociología) no ha pasado aún de la era de las construcciones y de las sintesis filosóficas" (Durkheim, 1982b: $1)^{30}$, atacando la relación con la realidad de algunas de sus concepciones: "¿Existen, realmente, las monomanías?" (Durkheim, 1982b: 23).

b) La constante definición en la introducción y primeros capítulos: "se llama suicidio toda muerte que resulta, mediata o inmediatamente, de un acto, positivo o negativo, realizado por la víctima misma" (Durkheim, 1982b: 5). En esta primera parte, la definición se constituye en guía y en otro punto de ruptura con la sociología hecha hasta el momento: "Los sociólogos están tan habituados a emplear las palabras sin definirlas" (Durkheim, 1982b: 105).

Así, El Suicidio adquiere su fuerza más por la demostración de lo que no son las causas de El Suicidio que por la demostración de las que se señalan como tales, siendo éstas las que posteriormente han sido el principal objeto de las críticas a la obra. Un trabajo de purificación que se desplegará por buena parte de la obra de Durkheim, lo que lleva a que Giner señale como principal labor del sociólogo francés la de descartar (Giner, 1995: 27).

El apartado introductorio se completa con la exposición de las fuentes de los datos. Final de la introducción que amplifica la declaración de principios y el ejercicio de ruptura con lo que puede considerarse la tradición. Quien escribe no es un pensador, que elabora sus argumentos a partir de un mero ejercicio de reflexión interior, sino un investigador, un ordenador de los datos de la realidad exterior al mismo ${ }^{31}$. Por esta razón y a diferencia de otros investigadores contemporáneos, Durkheim no exilia la metodología a los apéndices (Selvin, 1958: 607). La metodología se alza como único lugar del sujeto cognoscente ante lo trascendente.

El segundo gran apartado de El Suicidio está dedicado a combatir los argumentos que niegan la hipótesis principal, ejercitando lo que Lukes denomina sociología agresiva, fundamentado en el repaso crítico a los trabajos realizados.

Libro Primero, le lleva a avisar al lector que pudiera quedar abrumado en el inicio del Libro Segundo: "Los resultados del libro precedente no son puramente negativos» (Durkheim, 1982b: 131).

${ }^{30}$ Para Madge (1970), El Suicidio marca la distancia de la sociología frente a la filosofía.

${ }^{31}$ Posición que se extiende por la mayor parte de la obra de Durkheim y lo que le lleva a criticar a otros renombrados sociólogos. Por ejemplo, es crítico con Simmel en su artículo «La sociología y su campo científico" (Durkheim, 1960). Esta agresividad purificadora de Durkheim fue heredada por sus seguidores inmediatos, que no regateaban acusaciones contra el resto de la comunidad de investigadores sociales francesa, especialmente contra los seguidores de Le Play (Henri de Torunville, Jacques Bertillon, Emile Levasseur), como "diletantes incompetentes» (Clark, 1990: 111). 
Durkheim va rechazando toda una serie de causas directas del suicidio: sexo, enfermedad mental, alcoholismo, raza, clima, etc., bajo el esquema X (causa) --- Suicidio (efecto), hasta dar cabida a la hipótesis de la existencia de causas capaces de explicar lo que se tiene por causas directas e, incluyéndolas, explicar el propio suicidio ${ }^{32}$. Es a través de este extenso trabajo de purificación donde se encuentra el que, para Alpert $(1939,1958)$, es el principio metodológico fundamental de Durkheim: los hechos sociales deben relacionarse etiológicamente con otros hechos sociales. Una vez traspasada la frontera hacia lo no humano, no hay vuelta atrás; las cosas tienen su propia lógica en un mundo trascendente: "la totalidad de la metodología durkheimiana arranca de la convicción de que el principio de causalidad es aplicable al mundo social. Los "hechos sociales" no se producen arbitrariamente y el objetivo del sociólogo es, precisamente, superar el caos con que a primera vista se muestran tales hechos y descubrir su inteligibilidad subyacente» (Rodríguez Zúñiga, 1978: 17).

El patente rechazo de la tradición anterior, tanto la metodológica como la especializada en el tema, es, en sí mismo, un alarde de modernidad. Lo anterior no sirve, lo que hace necesario proponer algo nuevo, con lo que Durkheim realiza un ejercicio pleno de modernidad, pues: "Nadie es moderno si no ha sentido la belleza de este amanecer y no ha vibrado con sus promesas" (Latour, 1993: 60).

Es tal la energía purificadora promovida por Durkheim, que fija la mirada y la reflexión en aquello que rechaza, lo que apenas permite la mirada crítica sobre sus propios datos. Al respecto, hay que señalar que sólo recientemente se ha cuestionado con relativa fuerza la calidad de los datos utilizados por Durkheim en su estudio, sobre cuya posibilidad de sesgo él mismo da cuenta en una nota ${ }^{33}$. Pero, a pesar de ello, Durkheim persuade, hasta el punto que: "Durante mucho tiempo la sociología moderna ha creído que el indice de suicidio social de los protestantes es más alto que el de los católicos y el de éstos más que el de los judios. Esta idea que deriva de El Suicidio, no está empiricamente bien fundada» (Pope, 1976: 77). Ni los críticos de El Suicidio han rechazado notablemente los datos propuestos por Durkheim, centrándose sus críticas en las inferencias durkheimianas de los mismos, como señalan Van Poppel y Day (1996).

Siguiendo con la arquitectura de El Suicidio, cada capítulo se configura como un progresivo paso con respecto al anterior, generando la sensación de acumulación de conocimiento. Doble modernidad del informe, pues ya no sólo se presenta como ruptura con lo dicho previamente al mismo, sino que su estructura se configura como renovación en marcha, en la que lo dicho hasta un punto tiene como máximo horizonte de estabilidad el próximo párrafo. Una retórica en la que la presentación de nuevos datos y explicaciones amenaza

${ }^{32}$ Ha de tenerse en cuenta que Durkheim descubre las variables intervinientes, como la educación.

${ }^{33}$ Posibles sesgos que pueden haberse dirigido al hecho de que en unos países, los católicos, existan más obstáculos para registrar los suicidios como tales, mientras que este acto parece más admitido en los países protestantes. 
lo dicho anteriormente. Ello es evidente en los «cuadros resumen de los resultados precedentes» y en las conclusiones de cada capítulo, configurando un orden que se cierra sobre la conciencia de apertura. Es aquí donde juega un papel principal la discusión teórica: ir cerrando discusiones (aperturas) y abriendo-cerrando hipótesis, reformulando hipótesis a partir de la relación con los datos.

Los argumentos presentes en El Suicidio intentan vencer otros argumentos, retándolos a través de un ceremonial purificador: dejar los hechos "desnudos». Es aquí donde reside la fuerza persuasiva de un trabajo, que todavía se mantiene. Como señala Selvin: "Pocos, si alguno, de los últimos trabajos pueden competir con la claridad y poder con que Durkheim muestra ceremonialmente los hechos para testar y refinar su teoria» (Selvin, 1958: 607). La modernidad, presente en la asunción del dominio del trabajo de purificación, se convierte en clave de su éxito en la persuasión.

\section{EL TRABAJO DE LOS CUADROS ESTADÍSTICOS}

La apuesta por la modernidad contenida en El Suicidio no hubiera sido posible sin contar con un elemento, que durante todo el siglo XIX había mostrado su potencial ${ }^{34}$, como el análisis estadístico. Durkheim parte de tal potencial para estudiar la sociedad, alcanzando usos más sofisticados que los realizados por sus predecesores (Porter, 1986: 67), incluyendo uno de los fundadores del análisis estadístico, como Quetelet, quien ya había abordado la regularidad y estabilidad de los suicidios (Desrosières, 1993: 99) ${ }^{35}$. Si Le Play es el inventario presupuestario — no relaciona apenas nada, sólo colecciona y apunta- y Engels el inventario desde la testificación, Durkheim es la relación de hechos y comparación de sociedades en ese espacio acotado que son los cuadros estadísticos ${ }^{36}$.

La proyección modernizadora no reside sólo en que a través del análisis estadístico se pasa de la especulación a la proximidad a los hechos, como el propio Durkheim mantenía, sino que su protagonismo en el desarrollo del texto apoya de tal manera los restantes rasgos de modernidad que cabe considerarlo, en sí mismo, otro rasgo más, constituyendo la culminación del trabajo de purificación. Trabajo llevado a cabo por unos cuadros estadísticos que apenas aportan novedades, pues muchas de las correlaciones presentadas ya habían sido hechas (Giddens, 1993), y que, sin embargo, generan una forma de hacer en sociología.

${ }^{34}$ Para Latour: «La estadística es la mayor ciencia del siglo XIX» (Latour, 1994: 245).

35 Para Hacking (1991: 102), la selección del suicidio como objeto de investigación por parte de Durkheim estuvo propiciada por la montaña de datos existentes sobre el tema en la época. Durkheim articula así dos importantes fuentes: los avances en el análisis estadístico y la cantidad de datos sobre el suicidio.

${ }^{36}$ El papel de los cuadros-matrices para comparar datos interrelacionados en la institucionalización de las ciencias sociales es resaltado por Lazarsfeld (1960). 
Más que un útil, el análisis estadístico es parte del trabajo de purificación. A partir del mismo, Durkheim rebate los argumentos de sus antecesores en la explicación del suicidio, de los Morselli, Esquirol, Wagner, Prinzing, etc. Incluso enfrentándose a éstos, conserva los datos producidos por algunos de ellos y, sobre todo, el carácter protagonista de las tablas en el desarrollo de los argumentos. Un espacio que no se pone en cuestión, incluso cuando, utilizando un símil deportivo, se juega en el campo del contrario: "De las cifras mismas que nos da Morselli..." (Durkheim, 1982b: 93). Aceptación de las cifras que supone, de hecho, aceptación de los límites que conllevan para las argumentaciones distintas. De aquí que, tras la aceptación, la argumentación propia sale potenciada, siendo una de las principales virtudes de El Suicidio. El cuadro estadístico es el campo de la purificación y el campo donde se purifican los debates. Las reglas de juego del debate sociológico aparecen circunscritas al campo del análisis estadístico: "La cuestión está todavía sin resolver; hay que pedir su solución al análisis de los datos estadísticos» (Durkheim, 1982b: 88), propone Durkheim para dirimir una de las discusiones que establece sobre las causas del suicidio, asimilando el cuadro estadístico a un árbitro. Al igual que Dios no entra en el moderno y exclusivo espacio configurado por el laboratorio de Boyle (Latour, 1993), pues es el laboratorio el que dirime, tampoco entra en el cuadro estadístico.

Como campo, como espacio en el informe, es donde se dirimen la concepción del mundo, la sociología, el papel del sociólogo y el grado de conocimiento de los especialistas sobre un tema. Lo que no entra en el laboratorio estadístico es casuística moral, filosofía política o especulación. Al igual que las paredes del laboratorio separan, en los inicios de la modernidad (Latour, 1993), la ciencia de la filosofía política, en esta propuesta de segunda modernidad es la estadística la que separa la ciencia social de la filosofía social. Precisamente lo que diferencia a Durkheim de los usos anteriores de la estadística, ejercidos por físicos sociales como Quetelet, es que mientras éstos especulan entre la astronomía, el caos social y la matemática, sobre las posibilidades del instrumento, sin apenas aplicación a trabajos empíricos de tales especulaciones ${ }^{37}$; aquél lo toma como un campo donde dirimir discusiones sobre temas sustanciales y la fuerza de los argumentos. Por ello, más que un instrumento, el análisis estadístico aparece en Durkheim como el lugar desde el que hacer sociología ${ }^{38}$.

Quetelet no aplicó la especulación estadística a sus trabajos empíricos, limitándose a la distribución de frecuencias y la realización de tablas. Según Porter (1986: 53), el Quetelet que practica la estadística fue más sencillo que el Quetelet estadístico social.

${ }^{38}$ Viniendo de la observación astronómica, Quetelet tiene el convencimiento de que la estadística matemática era aplicable a todos los campos (del saber), situándose así por encima de ellos. Para Durkheim, la estadística es el campo (espacio cerrado) donde ha de aplicarse el saber. Cambio en relación a la idea de lo que es un campo, que implica un traslado desde la inmersión en la comunidad (familias de obreros, jornaleros, pescadores, etc., como hace Le Play) al laboratorio estadístico. Entrando en el laboratorio estadístico, con la asunción de la forma experimental, el referente se hace más externo y "autónomo» del observador, adquiriendo objetividad. Durkheim encuentra en este laboratorio el instrumento privilegiado para el esfuerzo común de la 
Además de la definición de un campo, que hace, para las ciencias de los individuos, las veces de los laboratorios para las ciencias de las cosas, las tablas aportan:

- La posibilidad de resumir la sociedad, de dar concreción a aquello de lo que se está hablando. Aun cuando gastada actualmente, sigue valiendo la metáfora de la tabla estadística como fotografía de una sociedad, asumiendo que es la sociedad, la forma de lo colectivo: "Si se quiere saber de qué distintas confluencias resulta el suicidio, considerado como fenómeno social, es en su forma colectiva, es decir, a través de los datos estadísticos, como hay que considerarlo desde el primer momento" (Durkheim, 1982b: 135). Esta función icónica ${ }^{39}$, de dar imagen al conjunto de una sociedad, está muy presente en El Suicidio: "se considera el conjunto de los suicidios cometidos en una sociedad dada" (Durkheim, 1982b: 8). Los cuadros estadísticos, como buena parte de las inclusiones icónicas en los informes, tienen por función reproducir a escala una totalidad para "alcanzar conclusiones incontrovertibles y luego extender las conclusiones que les parecen favorables a una escala mayor" (Latour, 1995: 256).

- Es la base para la construcción de la sociología, pues sólo viendo cómo varían los fenómenos abordados en distintas sociedades puede empezar a pensarse que son hechos sociales y, por lo tanto, ser objeto de un estudio especial que encaje en la sociología. Es el punto de partida, donde saltan las diferencias. En la génesis de los cuadros, no cabe lugar para la interpretación. Su génesis sale de la inmanente subjetividad. Las tablas no son sólo un espacio de equivalencia y comparabilidad. Son, sobre todo, un espacio que impone un imperio de objetividad en el espacio de la argumentación. La interpretación viene después, cuando se han confirmado las diferencias ${ }^{40}$. Por otro lado, la manipulación de los datos en la tabla hace de la sociología un oficio y la habilidad en su uso se convierte en una especie de arte, en el que el objeto es la sociedad objetivada.

- En la tabla estadística, el grado de objetivización que adquieren los hechos sociales es alto. Como se admitía en la época, la estadística es la ciencia

investigación empírica: «se realizan esfuerzos especiales para externalizar las observaciones del tipo llamado empirico, para dar a las investigaciones y sus resultados un referente externo, con el fin de recuperar para la presentación del resultado la forma de la experimentación» (Luhmann, 1996: 108).

39 Quienes se hayan dedicado a la investigación sociológica empírica por algún tiempo, habrán podido percibir la creciente importancia de los materiales icónicos en los informes: gráficos, esquemas, dibujos, etc., quedando las tablas como un elemento textual mediador, paso intermedio, entre la escritura con palabras y la proliferación de elementos icónicos. Pero en el final del siglo pasado, tal función icónico, presidida por la limpieza del cuadro, estaba en la tabla con datos estadísticos del informe.

${ }_{40}$ Es lo que hace Durkheim, por ejemplo, con respecto a católicos y protestantes: una vez confirmadas las diferencias de suicidios entre ambas doctrinas se introduce en la interpretación de este hecho con la ayuda de la comparación de las variaciones de las dos confesiones, siendo el libre examen la primera conclusión que explica. 
de los puros actos. En el cuadro estadístico, el hecho social se transparenta. Aislados, sumados y encerrados, consuman el trabajo de purificación ${ }^{41}$ y se inscriben como hechos en el texto. Aparecen fuera del discurso ${ }^{42}$. El cuadro estadístico es la máquina de inscribir la realidad (Latour, 1995: 251 y ss.) por parte de la sociología de Durkheim presente en El Suicidio. En la tabla, la sociedad es algo contable, conjunto de objetos entre los que pueden establecerse relaciones ideales, sin apariencia de impregnación de las creencias más inmediatas. En el cuadro estadístico, el suicidio adquiere objetividad, dejando a un lado el significado social implicado en su definición (Douglas, 1995: 83) ${ }^{43}$. Los problemas de la sociedad pasan por el cuadro estadístico, como las epidemias pasan por el laboratorio. Al pasar por el laboratorio, el ántrax se convierte en un microorganismo. Al pasar por el cuadro estadístico, el suicidio se convierte en una cosa. Si en la puerta del laboratorio de Boyle se detienen «la lógica, las matemáticas o la retórica" (Latour, 1993: 35) para quedarse sólo con the matter of fact, el cuadro estadístico deja a un lado la interpretación, la lógica y la retórica. Si el lector duda de las afirmaciones de Durkheim, ahí está la tabla-laboratorio para realizar la demostración. La sociedad se pone ante los ojos del lector. El autor pasa a ser un mero presentador (Latour, 1992: 74). La estadística es el laboratorio de la sociología de Durkheim ${ }^{44}$, de manera que lo que se resistía a ser observado científicamente, a pasar la frontera desde lo humano a lo no-humano, pueda hacerlo ${ }^{45}$.

- Grado de objetivización amplificado, además, por la forma de articularse con el resto del texto: la escritura no estadística (palabras) se refiere a la escritura estadística (tablas) como si fuese un ámbito exterior, ajeno. Es más, el autor parece desaparecer de la tabla. La mejor forma de que el lenguaje deje de ser un problema, como se destacaba en la época, sospechando de su papel mediador (Valverde, 1990), es hacerlo desaparecer entre los lutos de las tablas

${ }^{41}$ La purificación la realiza Durkheim con la máquina estadística. Las sentencias de Durkheim sobre la capacidad purificadora de las tablas estadísticas son frecuentes en Las reglas: «aunque no se preste inmediatamente a la observación, puede comprobarse muchas veces con ayuda de ciertos artificios del método; es incluso indispensable proceder a esta operación, si se quiere separar el hecho social de toda mezcla para observarlo en estado de pureza (...) la estadistica nos suministra el medio de aislarlos» (Durkheim, 1986: 38).

${ }^{42} \mathrm{Al}$ respecto, señala Desrosières: "La posibilidad de utilizar las dos dimensiones de la página del libro para cruzar y clasificar los objetos, permitiendo asi mirarlos simultáneamente, distingue radicalmente lo escrito de lo oral, la razón gráfica de la razón del discurso" (Desrosières, 1993: 32). Fuera del discurso, su potencial para imponerse a los contradiscursos es alto.

${ }_{43}$ Sobre el significado del suicidio como marco condicionante de la producción de datos estadísticos sobre el suicidio, véase Merllié (1992).

${ }^{44}$ Refiriéndose a un viaje del joven Durkheim a Alemania, Ramón Ramos hace hincapié en que: «Tal vez lo más decisivo del viaje fue su estancia en Leipzig, en el laboratorio de psicología experimental de Wundt, que era la institución pionera en Europa en la modernización de las ciencias sociales. La importancia de esa experiencia es enorme cara a la orientación posterior de la sociología durkheimiana» (Ramos, 1982: 19).

${ }^{45}$ Según Porter: «las leyes estadisticas fueron deliberadamente formuladas para extender la certe$z a$ de ciencias como astronomía y mecánica al conocimiento de fenómenos que hasta entonces se habian resistido a la investigación cientifica exacta» (Porter, 1986: 69). 
estadísticas. Lo poco que podría quedarle de "humano», como la autoría de la creación de la tabla, aparece constantemente borrado: no es humano ni lo que expone la tabla, ni la creación de la tabla, como si ésta tuviese su propia autonomía. Es como si fuesen los propios hechos los que se presentasen al lector. Como dice Gross (1990: 74), las tablas y cifras sirven al argumento científico llevando al lector más cerca de la experiencia sobre la que se apoyan los argumentos, añadiendo una especie de peso semántico.

Desde los presupuestos de Durkheim, la estadística es la ciencia y ésta el resultado de la disolución de la tradición. Hacer ciencia es hacer modernidad. Una modernidad necesaria (Durkheim, 1982b: 162 y ss.). Pero, desde los presupuestos de modernidad aquí planteados, el cuadro estadístico es el arma de purificación, de objetivización (deshumanización) del hecho social, más potente que podía haber encontrado y, por lo tanto, un ejercicio de modernidad en sí mismo.

\section{LA SOCIEDAD COMO NUEVO HÍBRIDO}

Al proponer tratar los hechos como cosas, Durkheim hace una declaración de modernidad, que, a la vez, busca reformar la Constitución de la modernidad, en términos de Latour. Recoge básicamente la lógica que inaugura la modernidad: la separación entre un mundo humano, inmanente, reservado a la política, y un mundo no-humano, reservado a la ciencia. Reconoce la funcionalidad de la frontera; pero ya no aparece tan de acuerdo en el contenido de los respectivos lados de la frontera: "lo que se juzga tan fácilmente inadmisible cuando se trata de los hechos sociales, se admite corrientemente respecto de los otros reinos de la naturaleza» (Durkheim, 1986: 22). Su propuesta, como la de la mayor parte de la sociología contemporánea del autor ${ }^{46}$, es poner del lado de los objetos, de lo no humano, la sociedad. Señala así que la frontera es fruto de un consenso; pero subraya la validez del mismo. Es más, puede entenderse como la ampliación de la parte «reservada». Con tal ampliación, que conlleva la autonomía (trascendencia) de la sociedad ${ }^{47}$, el científico social se reserva un espacio autónomo. Tal principio rige El Suicidio, especialmente en sus primeras secciones.

El suicidio se presenta como un objeto con sus propias leyes y movimientos, al igual que los bacilos, protagonistas de la práctica científica del momento: "el suicidio se detiene un instante" (Durkheim, 1982b: 97), "la marcha de los suicidios» (Durkheim, 1982b: 103). El suicidio, como hecho social, como las representaciones, tiene vida propia.

46 La sociología contemporánea a Durkheim busca declaradamente ser una imitación de la ciencia natural (Tufts, 1993: 10)

${ }^{47}$ Los hechos sociales constituyen una «naturaleza definida que se impone» (Durkheim, 1986: 28). 
El dominio absoluto del trabajo de purificación, objetivización, separación y prohibición de híbridos entre humanos y no humanos es lo que define a la modernidad, según Latour; pero "cuanto más prohibimos la concepción de los híbridos más se posibilita su proliferación» (Latour, 1993: 27), pues, después de cosificada la sociedad, ¿cómo podemos actuar siendo cosas?, ¿cómo podemos ser sujetos siendo objetos? Se abre una tensión en la que se reconocen las reformas necesarias, pues es el papel de la sociología; pero no se muestran los reformadores. El carácter fundacional de la obra de Durkheim es, además, un importante obstáculo para mantenerse en la constante purificación, en el solo empleo del "estilo sin estilo", como estilo de la ciencia (Gustfield, 1976).

Es en la última parte de la obra donde ha de darse el desenlace del informe moderno. Pues bien, el último libro de El Suicidio (Libro III) está regido por el trabajo de traducción. En su poética, un trabajo centrado en tropos como «la sociedad queda herida», "templado moralmente», «esfuerzo enfermizo» (del Estado), «moléculas líquidas» (individuos) o «invadir la conciencia». Dominio de la traducción en la resolución de la tensión entre lo inmanente (humano) y lo trascendente (el mundo de las cosas, lo no humano). Durkheim resuelve tal tensión implicando su concepción política y su concepción de la sociología a través de la polaridad normal (trascendente) y patológico (inmanente). El principio durkheimiano que acentúa la existencia propia del hecho social (Durkheim, 1986: 46), el tratar los hechos sociales como cosas, deja a éstos, en principio, como algo trascendente, ajeno a las intenciones y práctica de los humanos. ¿Para qué sirve entonces observar lo que parece un proceso con sus propias leyes, ajenas a las intenciones de los hombres? Es aquí donde Durkheim utiliza la referencia de la medicina y la separación entre lo normal y lo patológico. La ciencia adquiere su proyección práctica diferenciando entre lo normal, sobre lo que nada puede hacerse puesto que sigue sus propias leyes, y lo patológico, sobre lo que cabe hacer algo. Camino confuso, distante de la claridad purificadora, que provoca la debilidad de las recomendaciones de actuación presentes en El Suicidio. El informe ha de proponer remedios para abordar las orgánicas disonancias que produce la evolución de la sociedad. Sin embargo, ha de señalarse el carácter abstracto de las recomendaciones de Durkheim, dirigidas hacia la propia sociedad, sin sujetos concretos. Como dice Bryant, Durkheim se mostró «incapaz de sugerir cómo llevar a cabo las reformas que él mismo proponía debian ser realizadas» (Bryant, 1985: 35).

Como concreción de una disciplina moderna, el suicidio se presenta como algo que debe ser estudiado con independencia de la voluntad (conciencia) de los individuos implicados, salvo, claro está, la voluntad de matarse. Buena parte del trabajo de purificación de las primeras páginas y la discusión con otros autores está destinado a vaciar el suicidio de la conciencia de los suicidas, haciéndolo una cosa, representándolo como el producto de una ley. La modernidad está en ese paso de frontera que consiste en crear el vacío, al que tantos esfuerzos se dedicaron. Antes, en el ámbito de la física, de los objetos naturales. Ahora, se propone para el estudio de la sociedad. Es como si la sociología, 
para ser reconocida como ciencia, requiriese también de ese vacío. Sin embargo, la otra cara de su institucionalización es pragmática: ha de servir para actuar. No sólo ha de ser formalmente moderna, sino que ha de procurar informes para actuar, debiendo volver así al mundo de lo humano.

Tensión entre la prohibición de híbridos y la exigencia de actuación del informe reconocida por el propio Durkheim, que hace del hecho social un lugar de encuentro entre lo ajeno y lo propio, entre el resultado de leyes inexorables y el ejercicio de voluntad humana, entre lo rígido y lo modificable, pues lo modificable es el objeto último. Así, Moya señala a propósito de los objetivos últimos del programa de Durkheim: "una praxis politica capaz de remediar la patológica situación social sólo es posible a partir de la investigación de las leyes científicas que rigen la sociedad humana» (Moya, 1971: 32). El método propuesto por Durkheim hace del hecho social un híbrido, en el que se puede ejercer la voluntad y que, a la vez, "considera los hechos sociales como cosas cuya naturaleza, por dócil y maleable que sea, no es modificable a voluntad" (Durkheim, 1986: 12), con lo que el hecho social queda como un híbrido entre la ley natural y la voluntad humana.

Durkheim, constituyendo la sociedad en un híbrido, no hace sino lo que hacen los modernos, pues "la Constitución moderna permite la proliferación expansiva de los hibridos al mismo tiempo que niega su existencia e incluso su posibilidad» (Latour, 1993: 59). Siguiendo al mismo Latour, los modernos movilizan la naturaleza, cosifican lo social y sienten la presencia espiritual de Dios, aun cuando mantienen firmemente que la naturaleza se nos escapa, que la sociedad es obra nuestra y que Dios no interviene ya en ella. Los híbridos están desde el principio de la modernidad. Tras la reforma propuesta por Durkheim, incluso se empiezan a reconocer.

El trabajo de traducción completa y justifica el trabajo de purificación, constituyendo un mismo proceso. La constante separación de conceptos y prácticas desarrollada a lo largo del libro sólo cobra sentido desde su proyección pragmática. Proyección que es lo que procura el esfuerzo de traducción.

Lo que aquí interesa resaltar es que, a pesar del obstáculo lógico-constitucional, aborda las posibles salidas a algo que se vive como un problema: el aumento de los suicidios. El informe ha de implicarse en la operatividad, que es lo que le exige Bryant en la cita anterior. Es lo que se exige al informe sociológico moderno: deducir qué es lo que pueden hacer los sujetos a partir de una situación y la ley de los procesos. Cuestión que le diferencia de los trabajos sociográficos, dominados por los encargos de las comisiones parlamentarias e institutos oficiales estadísticos (Maus, 1973), en los que la colección de descripciones no deja lugar a la sugerencia, o, como en el caso de Engels, no se deja margen a la acción. La exigencia operativa rompe la purificación, pero, al mismo tiempo, la justifica, al igual que el ejercicio de trascendencia es justificado desde la inmanencia. El trabajo de purificación de la realidad social queda revelado como táctica del sociólogo para traducir las posibilidades colectivas de acción. La propuesta de la modernidad de ese "como trascendente» 
está limitada por la operatividad concreta de la misma modernidad. No se trata de una separación gratuita entre lo humano y lo no humano, como parece describir Latour, sino que está inserta en lo concreto, en una práctica llena de complejos híbridos. Así se constituye la traducción práctica como un nivel superior a la purificación y el trabajo clandestino y extraoficial, como de un nivel superior a la constitución oficial de la modernidad.

Doble juego entre lo trascendente y lo inmanente, por el que la necesidad del cierre puede explicarse por la necesidad de apertura: hay que cerrar la realidad, a partir del método, para poder actuar. Pero, también, donde la necesidad de apertura-traducción puede explicarse por la necesidad de cierre-purificación: el método sociológico sólo puede instituirse en la medida que muestre su emparejamiento pragmático con otras ciencias con una institucionalización consolidada, en la medida que pueda resolver, como ellas, problemas prácticos, dejando abierta a una traducción continua — basada, en última instancia, en la unidad positivista del método- sus quehaceres y conceptos. Si la necesidad de actuación le lleva al método, la fe en el método le lleva a las propuestas de actuación: "esa fe en la razón conduce necesariamente hacia la acción, lleva en sí un rechazo radical de las concepciones de la sociología como labor de especulación o erudición sin posibilidad de incidencia práctica sobre la sociedad" (Rodríguez Zúñiga, 1978: 10). El método sirve para purificar y, como referencia básica del trabajo científico, como punto de partida para la traducción ${ }^{48}$.

Si la teoría y la metodología habían conducido la investigación y el desarrollo de la escritura de El Suicidio a través del trabajo de purificación, el reconocimiento de las dificultades para operar en una realidad compleja conduce a una apertura constante que lleva hasta la propia reflexión teórica. Por ello, El Suicidio funda el programa durkheimiano, proyectando sus conclusiones -en especial la de la anomia creciente- sobre su sociología política, su sociología de la educación e incluso su sociología de la religión (Marks, 1974): lo que puede y lo que no puede hacerse. Las dificultades para operar llevan al reconocimiento de los límites actuales del trabajo científico-social para proponer un orden sobre su realidad y, al mismo tiempo, lo que no deja de ser una declaración de modernidad, la asunción de que los resultados futuros de este trabajo lograrán su fruto: "Lo que se precisa es investigar en el pasado los gérmenes de vida nueva que contenía y apresurar su desarrollo" (Durkheim, 1982b: 440). Paradójica característica del informe moderno por la que se asumen las limitaciones de los resultados, sobre todo de cara a la acción operativa, pero se hace desde la apertura hacia nuevas investigaciones, declarándolas necesarias.

48 Como base purificadora desde la que parte la traducción, el método «limpiará» los conceptos que se irán progresivamente articulando con otros fenómenos sociales a través de códigos comunes cada vez más amplios. Así, Durkheim emplea el código común del estado de la conciencia colectiva para emparejar situaciones de distintas instituciones sociales: el suicidio, la familia, la educación, la política, los grupos profesionales, etc. 


\section{CONCLUSIONES}

Durkheim no sólo habla del hombre moderno, su aislamiento, la alienación, la falta de autoridad moral, subrayando los aspectos más lúgubres de la modernidad, sino que lo hace en clave moderna, al menos en clave de informe moderno. No sólo habla de la modernidad y sus consecuencias, como ha sido brillantemente subrayado por diversos autores ${ }^{49}$, sino desde la modernidad, lo que implica una forma de entender la escritura en general — como combate abierto frente a otros escritores y otras maneras de hacer sociología, y búsqueda de alianza con el lector y la sociedad en su conjunto- y la escritura de la investigación en particular. Una modernidad en la escritura de la investigación dominada por la doble práctica de purificar, pudiéndose interpretar El Suicidio como un trabajo de purificación de los datos desde el estilete de la teoría y el análisis estadístico. La escritura de la investigación de Durkheim toma así unas características que la diferencian de las escrituras previas. A este respecto, se han tomado como referencia los trabajos de Engels y Le Play y algunos precedentes de la propia escritura de investigación de Durkheim. Las diferencias entre estos informes y el que realiza Durkheim en El Suicidio son notables.

Los rasgos de modernidad contenidos en El Suicidio han sido: ruptura con el presente y lo anterior; el protagonismo del cuadro estadístico y la subordinación de las propuestas formales a la operatividad pragmática inmediata, asumiendo este último rasgo la siempre difícil articulación entre la modernidad como proyecto abstracto y la modernidad como reconocimiento de los límites concretos para la realización de tal proyecto. Tales rasgos de modernidad han aparecido como el fruto, en la escritura de la obra, de la articulación entre dos trabajos fundamentales: el trabajo de purificación y el trabajo de traducción.

Se ha visto cómo El Suicidio está dominado por el trabajo de purificación, siendo éste el que otorga modernidad y, a la vez, fuerza persuasiva. Un trabajo de purificación que facilita el éxito de la intención de ruptura y explica el protagonismo del análisis estadístico. Sin embargo, el trabajo de traducción resurge a la hora de plantear las recomendaciones derivadas de la investigación. Por ello, cabe afirmar que la sociología se hace moderna no siendo puramente (abstractamente) moderna, ya que, en última instancia, su institucionalización depende también de su proyección pragmática. De esta manera, el informe moderno de la investigación social está envuelto en la paradoja de tener que observar los fenómenos como si éstos siguiesen sus propias leyes, como si fuesen trascendentes a la acción humana, a la acción de los sujetos, y, a la vez, hacerlos inmanentes a la tal acción. Por ello, en su arquitectura, poética y pragmática, El Suicidio es un texto plenamente moderno, si es que, aun cuando sea alguna vez, hemos sido modernos.

49 Tal vez los autores que más han acentuado este aspecto han sido Nisbet $(1969,1974)$ y Giddens (1974, 1979). 


\section{BIBLIOGRAFÍA}

AlPERT, Harry (1938): «Explaining the Social Socially», Social Forces, XVII, pp. 361-365.

- (1958): «Emile Durkheim: enemy of fixed psychological elements», American Journal of Sociology, 63 (6), mayo, pp. 662-664.

Bauman, Zygmunt (1990): Modernity and ambivalence, Cambridge, Polity.

- (1992): Intimations of postmodernity, Nueva York, Routledge.

Besnard, P. (1976): «Anti-ou anté durkheimisme? Contribution au débat sur les statistiques officielles du suicide», Revue Française de Sociologie, XVII, 2, abril-junio, pp. 313-341.

Bryant, Chistopher G. A. (1985): Positivism in social theory and research, Nueva York, St. Martin's Press.

BOUDON, Raymond (1974): La crisis de la sociología, Barcelona, Laia.

CALINESCU, Matei (1987): Five faces of modernity: modernism, avant-garde, decadence, kitsh, postmodern, Durham, Duke University.

Callon, Michel (ed.) (1989): Les Sciences et ses reseaux. Genèse et circulation des faits scientifiques, París, La Découverte.

- (1995): «Algunos elementos para una sociología de la traducción: la domesticación de las vieiras y los pescadores de la bahía de St. Brieuc», en J. M. Iranzo, J. R. Blanco, T. González de la Fe, C. Torres y A. Cotillo (coords.), Sociología de la ciencia y la tecnología, Madrid, CSIC.

Certeau, Michel de (1975): L'écriture de l'histoire, París, Gallimard.

Clark, Terry N. (1990): «Emile Durkheim and the Institutionalization of Sociology in the French University System», en Peter Hamilton (ed.), Emile Durkheim. Critical assessments, vol. 1, Londres y Nueva York, Routledge.

Desrosières, Alain (1993): La Politique des grands nombres. Histoire de la raison statistique, París, La Découverte.

Douglas, Jack D. (1993): "The Sociological Analysis of Social Meanings of Suicide», en Peter Hamilton (ed.), Emile Durkheim. Critical assessments, Londres y Nueva York, Routledge.

Durkheim, Emile (1960): «Sociology and Its Scientific Field», en Kurt H. Wolff (ed.), Emile Durkheim, 1858-1917, Columbus, The Ohio State University.

- (1975): «Suicide et natalité: étude de statistique morale», en Textes, París, Minuit.

- (1982a): La división del trabajo social, Madrid, Akal.

- (1982b): El Suicidio, Madrid, Akal.

- (1986): Las reglas del método sociológico, Barcelona, Orbis.

ELLIOT, Anthony (1996): Subject to ourselves: social theory, psychoanalysis and postmodernity, Cambridge, Polity Press.

Galtung, Johan (1973): Teoría y métodos de la investigación social, Buenos Aires, Eudeba.

GEerTZ, Clifford (1989): El antropólogo como autor, Barcelona, Paidós.

Gellner, Ernest (1994): Posmodernismo, razón y religión, Barcelona, Paidós.

GIDDENS, Anthony (1974): El capitalismo y la moderna teoría social, Madrid, Guadarrama.

- (1979): Central Problems in Social Theory, Londres, MacMillan.

- (1990): The consequences of modernity, Cambridge, Polity (traducción en Alianza).

- (1993): "The Suicide Problem in French Sociology», en Peter Hamilton (ed.), Emile Durkheim. Critical assessments, Londres y Nueva York, Routledge.

- (1995): Modernidad e identidad del yo, Barcelona, Península.

GINER, Salvador (1995): Sociología, Barcelona, Edicions 62.

Gross, Alan G. (1990): The Rhetoric of Science, Londres, Harvard University Press.

GustFielD, Joseph (1976): «The Literary Rhetoric of Science: Comedy and Pathos in Drinking Drives Research", American Sociological Review, n. ${ }^{\circ} 41$, pp. 16-34.

HACKING, Ian (1991): La domesticación del azar, Barcelona, Gedisa.

Hamilton, Peter (1993): Emile Durkheim. Critical assessments, Londres y Nueva York, Routledge.

JAMESON, Fredric (1991): Postmodernism or the cultural logic of late capitalism, Durham, Durge University Press. 
JONES, Robert Alun (1994): «Ambivalent cartesians: Durkheim, Montesquieu, and Method», American Journal of Sociology, 100 (1), julio, pp. 1-39.

KAPLOV, Theodore (1974): La investigación sociológica, Barcelona, Laia.

LATOUR, Bruno (1992): Ciencia en acción: cómo seguir a los cientificos e ingenieros a través de la sociedad, Barcelona, Labor.

- (1993): Nunca hemos sido modernos, Madrid, Debate

- (1995): «Dadme un laboratorio y moveré el mundo», en J. M. Iranzo, J. R. Blanco, T. González de la Fe, C. Torres y A. Cotillo (coords.), Sociología de la ciencia y la tecnología, Madrid, CSIC.

LAZARSFeld, Paul F. (1960): Philosophie des sciences sociales, París, Gallimard.

Lazarsfeld, P. F., y Oberschall, A. R. (1965): «Max Weber and Empirical Social Research», American Sociological Review, n. ${ }^{\circ}$ 30, pp. 185-199.

Lampe, G. W. H. (1987): A Patristic Greek Lexicon, Nueva York, Oxford.

Le Play, Frédéric (1989): La Méthode sociale, París, Meridiens Klinckseck.

- (1990): «Familia campesina de Revilla de Camargo (Santander), 1840-1847», en F. LE PLAY, Obreros y campesinos del Norte de España, Madrid, Ministerio de Agricultura, Ganadería y Pesca.

LLEDÓ, Emilio (1978): Lenguaje e historia, Barcelona, Seix Barral.

LOZANO, Jorge (1987): El discurso histórico, Madrid, Alianza.

Luhmann, Niklas (1996): La ciencia de la sociedad, México, Anthropos-Universidad Iberoamericana.

LYON, David (1996): Postmodernidad, Madrid, Alianza.

LYOTARD, Jean-François (1990): La postmodernidad (explicada a los niños), Barcelona, Gedisa.

MADGE, John (1970): The origins of Scientific Sociology, Londres, Tavistock.

MARKS, Stephen R. (1974): «Durkheim's Theory of Anomie», American Journal of Sociology, 80 (2), septiembre.

MaUS, Heinz (1973): «Prehistoria de la investigación social empírica», en R. König (ed.), Tratado de sociología empírica, Madrid, Tecnos, pp. 41-60.

Merllie, Dominique (1987): "Le suicide et ses statistiques: Durkheim et sa posterité», Revue Philosophique, n.o 3, pp. 303-325.

- (1992): «Suicides: modes d'enregistrement», en Jean-Louis Besson (ed.), La cité des chiffres, París, Autrement.

Miley, James D., y Micklin, Michael (1972): «Structural Change and the Durkheimian Legacy: A Macrosocial Analysis of Suicide Rates», American Journal of Sociology, 78 (3), noviembre, pp. 657-673.

MoYa, Carlos (1971): Teoría sociológica. Una introducción crítica, Madrid, Taurus.

MULKAY, Michael (1995): «La visión sociológica habitual de la ciencia», en J. M. Iranzo y otros (coords.), Sociología de la ciencia y la tecnología, Madrid, Centro Superior de Investigaciones Científicas.

NisBET, Robert (1969): La formación del pensamiento sociológico, Buenos Aires, Amorrortu, 2 vols.

- (1974): The Sociology of Emile Durkheim, Nueva York, Oxford University Press.

PARSONS, Talcott (1968): La estructura de la acción social, Madrid, Guadarrama.

Perelman, Ch. y Olbrechts-Tyteca, L. (1989): Tratado de la argumentación, Madrid, Gredos.

Pope, Withney (1976): Durkheim's «Suicide»: A Classic Analyzed, Chicago, University of Chicago.

POPPEL, Frans van, y DAY, Lincoln H. (1996): "A test of Durkheim theory of suicide -without commiting the "ecological fallacy" ", American Sociological Review, 61 (3), junio, pp. 500507.

PORTER, Theodore M. (1986): The rise of statistical thinking 1820-1900, Princeton, Princeton University Press.

Ramos, Ramón (1982): «Introducción», en E. Durkheim, El socialismo, Madrid, Editora Nacional.

Rodríguez ZúNiga, Luis (1978): Para una lectura crítica de Durkheim, Madrid, Akal, 1978. 
RILEY, Matilda White (1963): Sociological Research I, Nueva York, Harcourt, Brave and Wold. RITZER, George (1993): Teoría sociológica contemporánea, Madrid, MacGraw-Hill.

RobINSON, Williams S. (1950): «Ecological correlations and the behavior of individuals», American Sociological Review, 15.

SELVIN, Hanan C. (1958): «Durkheim's Suicide and problemas of empirical research», American Journal of Sociology, 63 (3), mayo, pp. 607-619.

Shapin, S., y Shaffer, S. (1985): Leviathan and the Air-Pump, Princeton, Princeton Universtiy Press.

Toulmin, Stephen (1990): Cosmopolis: The hidden agenda of modernity, Nueva York, Free Press. TufTS, James H. (1993): «Recent Sociological Tendencies in France», en Peter Hamilton (ed.), Emile Durkheim. Critical assessments, Londres y Nueva York, Routledge.

VAlverde, José María (1990): Viena, fin de imperio, Barcelona, Planeta.

\begin{abstract}
This paper analyzes why Suicide is today a model of research report, one hundred years after being first published. In doing so, it relies on the writing of this monograph that is considered as a writing that founds the modernity in Sociology. Before, it has been brought into relief the linguistic nature of the Durkyeim's project. However links between this characteristic of the durkheimian project and the total project no have been established. This work has mainly followed the original Bruno Latour analysis about modernity. Latour describes modernity as the constituting of the difference between nature and culture. Translation and purification are the two fundamental practices for building that difference. After revising two kinds of earliers sociological writings -Engels and Le Play - it is described how Suicide applies translation and purification.
\end{abstract}

